\title{
Study on Earthquake Damage Distribution of Multistory Masonry Buildings
}

\author{
Zhou Qiang ${ }^{1, *}$ and Sun Bai-tao ${ }^{2}$ \\ ${ }^{1}$ School of Civil Engineering and Architecture, Nanchang University, Nanchang 330031, China \\ ${ }^{2}$ Institute of Engineering Mechanics, China Earthquake Administration, Harbin 150080, China
}

\begin{abstract}
The main components which affect the earthquake damage grades classification of multistory masonry buildings and the damage characters are summarized and analyzed through the statistics and analysis of a large number of previous earthquake damage data. According to the standard of earthquake damage grades classification, the damage numbers of each component of multistory masonry buildings under different earthquake damage indexes are analyzed quantitatively and the calculation formulas based on the relationship between the damage numbers of components and the earthquake damage index under different cases are given; Based on the structural analysis of multistory masonry buildings and the research of earthquake damage data, the calculation formulas of the earthquake damage distributions in different floors and main components' different positions on the same floor of multistory masonry buildings are given, which provides us a platform to objectively understand the earthquake damage distribution of multistory masonry buildings; The earthquake damage distribution is an important factor to affect the realistic degree of the 3-D damage models in the scene simulation system for earthquake disaster, this paper also provides a theoretical basis for the modeling of the 3-D damage models of multistory masonry structure; Finally, the earthquake damage distribution of the bearing wall of a five-storey masonry building in the minor damage has been given as an example.
\end{abstract}

Keywords: Earthquake damage distribution, earthquake damage index, multistory masonry buildings, quantitative analysis, structural components.

\section{INTRODUCTION}

The seismic fortification of building is based on the scientific level and the premise of economic conditions. The seismic fortification goal of our country's seismic code is that "undamaged under small earthquakes, repairable under middle earthquakes, no collapse under large earthquakes", which is consistent with lots of other countries' seismic thought. Because of the brittle material's properties, which have low shear, tensile and flexural strength and the bad connection, its ability to resist earthquake disasters is poor. From all previous seismic surveys both in our country and in abroad, it can be found that the damage rate of the masonry structure buildings are higher [1-3]. It is inevitable for structure to have damages in the destructive earthquakes, all previous earthquake damages show that different types of building structures meet certain distribution of damage, but the related research work was carried out less at present.

Earthquake disaster emergency rescue is one of the important contents of earthquake preparedness and disaster reduction, and it is also a professional job. The many years' experiences in our country and in abroad suggest that a full understanding of the rescue site environment, structure type and structure failure form play an important role in giving

*Address correspondence to this author at the School of Civil Engineering and Architecture, Nanchang University, Nanchang 330031, China;

Tel: (+86)18166040737; E-mail: zhouqiang@ncu.edu.cn full play to the effectiveness of earthquake emergency rescue. With the development of computer technology, the earthquake field disaster scene simulation has become an inevitable trend $[4,5]$, it can greatly improve the rescuers' training skill and make it more scientific and targeted. Threedimensional disasters model of building is an important part of earthquake field disaster scene, among them, the earthquake damage distribution is an important factor of earthquake field disaster scene in three dimensional disasters model of building.

On the basis of a large number of earthquake damage information, and through structure analysis and expert experiences' correction, this paper study the earthquake damage distribution of multistory masonry structure under different damage levels, and give the ideal formula of the earthquake damage distribution, which can provide an objective understanding of the earthquake damage distribution, and provide theoretical basis for the establishment of three-dimensional disasters model for multistory masonry structure in the earthquake field disaster scene simulation system at the same time.

\section{THE QUANTITATIVE ANALYSIS OF EACH COMPONENT'S EARTHQUAKE DAMAGE}

The current standard of building earthquake damage level has been considered as the main bearing and the non bearing component damage of the structure. For the different com- 
Table 1. Classification standard of earthquake damage to multistory masonry structure.

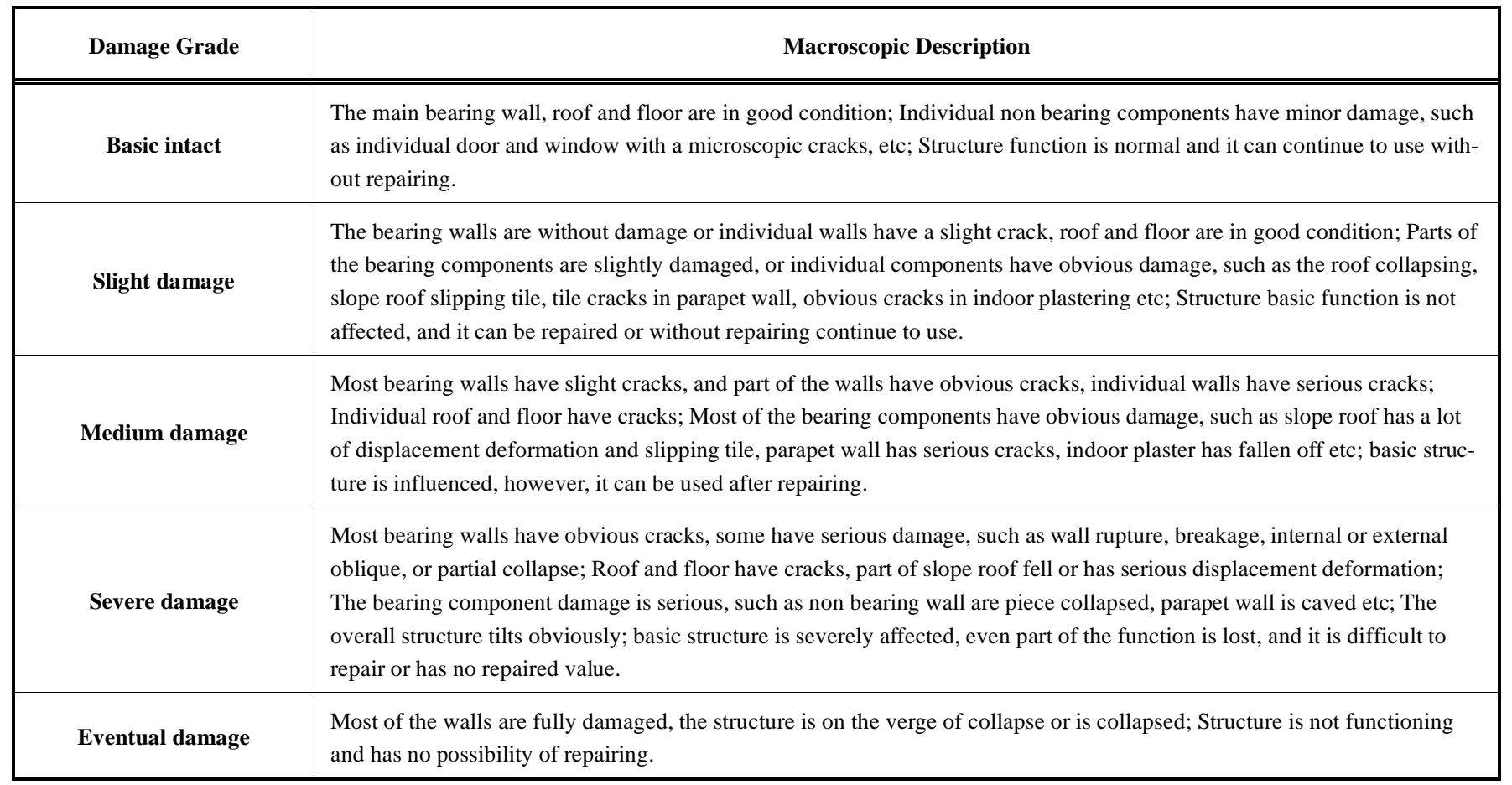

ponents of the structure, in the same or different earthquake damage level, the number of earthquake damage has its own standard. Earthquake damage index is an intuitive way in measuring structural earthquake damage, it combines the building damage grade with earthquake damage index, so each damage level of structure corresponds to a scope of earthquake damage index, and the earthquake damage severity of the same damage level of structure is distinguished by earthquake damage index. In fact, the earthquake damage severity of the structure is measured by number of component damage, and then there exists a corresponding relationship between damage quantity and earthquake damage index.

\subsection{The Classification Standard of Multistory Masonry Structure Earthquake Damage Level}

Experts in our country and in abroad have given many damage grade classification methods and standard of buildings and special structures [6-12], the reference [13] is the latest national standard, referring to this standard, multistory masonry structure's earthquake damage grade is divided by the following standards in Table $\mathbf{1 .}$

\subsection{The Main Components Affecting the Structure's Earthquake Damage Grade}

According to the different levels of earthquake damage of multistory masonry structure in Table $\mathbf{1}$, the components which effect the multistory masonry structure's earthquake damage grade are divided into bearing wall, non bearing component, floor or roof, a total of three, and they are represented with $m=1,2,3$ respectively. Among them, non bearing component includes enclosure wall, self-bearing wall, parapet wall, and other decorative component, etc.

\subsection{Quantitative Analysis of Seismic Damage}

\subsubsection{The Number Classification of Components Damage and Earthquake Damage Index}

In order to get the total number $N_{m}$ of each kind of component of multistory masonry, we divide the components, such as walls, floor (roof) into individual components through the building's bay, depth and floor height, it means that the component, which belongs to different bays, depths and floors, is seen as different individuals, such as building's longitudinal wall, it is divided into many parts by each layers of floor and cross walls, we consider different parts as different individuals. The references [13-16] show that the damage amount of structural component can be defined by $\left[P_{n 1}, P_{n 2}\right]$ (where $n=1,2,3$ ) one by one to represent the damage amount ranging from 0 to $10 \%$ (individual), $10 \%$ to $50 \%$ (partially), $50 \%$ to $100 \%$ (most).

Earthquake damage index is a quantitative representation of structural damage level. Usually 1.0 indicates collapsed, 0 indicates intact, among them, according to the need, it is divided into several earthquake damage levels which can be expressed by appropriate number from 0 to $1.0[15,16]$. The range and its median of earthquake damage index of five damage levels are shown in Table 2 [15-18].

We use the letter $d=1,2,3,4,5$ to indicate successively the five different damage levels, and $\left[D_{d 1}, D_{d 2}\right]$ to indicate the ranges of damage index which is in the damage level $d$.

\subsubsection{Classification Standard and Scale Factor of Earth- quake Damage Type}

The component damage (except collapse) of multistory masonry structural is presented mainly in the form of cracks, 
Table 2. The range of earthquake damage index corresponding to different damage levels.

\begin{tabular}{|c|c|c|c|c|c|}
\hline Damage Level & Basic Intact & Slight Damage & Medium Damage & Severe Damage & Eventual Damage \\
\hline \hline The median of damage index & 0 & 0.2 & 0.4 & 0.7 & 1.0 \\
\hline The range of damage index & {$[0,0.1]$} & {$[0.1,0.3]$} & {$[0.3,0.55]$} & {$[0.55,0.85]$} & {$[0.85,1.0]$} \\
\hline
\end{tabular}

Table 3. Classification standard and scale factor of earthquake damage type.

\begin{tabular}{|c|c|c|c|c|}
\hline \multirow{2}{*}{$\begin{array}{c}\text { Earthquake Dam- } \\
\text { age Type }\end{array}$} & Classification Standard & \multicolumn{3}{|c|}{ Seismic Damage Type and Scale Factor } \\
\cline { 3 - 5 } Light cracks & $\begin{array}{c}\text { The width is not more than } 2 \mathrm{~mm} \text { and the length } \\
\text { is not more than } 1.5 \mathrm{~m}\end{array}$ & 0.8 & -- & -- \\
\hline \hline Obvious cracks & $\begin{array}{c}\text { The width is greater than } 2 \mathrm{~mm} \text { or the length is } \\
\text { greater than } 1.5 \mathrm{~m}\end{array}$ & 0.5 & 0.3 & 0.2 \\
\hline Serious cracks & $\begin{array}{c}\text { The width is greater than } 2 \mathrm{~mm} \text { and the length is } \\
\text { greater than } 1.5 \mathrm{~m}\end{array}$ & 0.4 & 0.4 & 0.1 \\
\hline
\end{tabular}

according to the damage strength of multistory masonry structure, the earthquake damage types are divided into light cracks (minor damage), obvious cracks (obvious damage), serious cracks (local crisp fragile), collapse (crash down), using $l=1,2,3,4$ to represent different degrees of structural damage.

The references [6, 13, 19] and extent of the Technical Guidelines of Earthquake Damage Discrimination for Rural Housing in Sichuan which was used after the Wenchuan M8.0 earthquake set the classification standards for different types of multistory masonry structure damages, then we make quantitative analysis for different types of damages, and give the damage category and their respective percentage through the damage statistics, as shown in Table $\mathbf{3}$.

\subsubsection{Correspondence Between the Amount of Damaged Components and the Seismic Damage Index}

In combination with correspondence between different damage levels and indexes, and the definition of different damage level of multistory masonry structure in Table $\mathbf{1}$, the conclusion can be drawn that in the damage level $d$, the multistory masonry structure in the component $m$ appears to be damage $l$ (in this case the numbers range of component damage $\left[P_{n 1}, P_{n 2}\right]$ is determined), when damage index is $D_{d}$, component damage percentage is calculated as formula (1).

$P_{m}\left[D_{d} \mid l\right]=P_{n 1}+\left(\frac{P_{n 2}-P_{n 1}}{D_{d 2}-D_{d 1}}\right)\left(D_{d}-D_{d 1}\right)$

Thus, corresponding to a certain damage index $D_{d}$ ( $D_{d} \in\left[D_{d 1}, D_{d 2}\right]$ ), we can calculate fixed value of the number percentage of the damaged components $P_{m}\left(P_{m} \in\left[P_{n 1}, P_{n 2}\right]\right)$. Taking the bearing walls which suffered a slight damage as an example, in this case, $d=2, m=1$, $l=1$, the percentage expression of the slight cracks in bearing walls is $P_{1}\left[D_{2} \mid 1\right]=0.5\left(D_{2}-0.1\right)$. When given any $D_{2}$ ( $D_{2} \in[0.1,0.3]$ ), we can calculate the corresponding value of $P_{1}\left[D_{2} \mid 1\right]$ in the range $[0,10 \%]$.

\section{EARTHQUAKE DAMAGE DISTRIBUTION OF MULTISTORY MASONRY BUILDINGS}

In order to create a lot of earthquake disaster models quickly and realistically to achieve the fast simulation of seismic disaster scene, and in order to provide reliable reference for emergency rescue and aid decision making, the distribution of damage on different floors of the house should be given quickly. It should be pointed out that the stress condition of multistory masonry structure is very complex during the seismic action [20-23]. Especially some structural components could develop inelastic deformations or may exhibit brittle failure. However, the stress condition and the crack development of the structure components are not clear enough now. Considering the urgency of the scene simulation of earthquake disasters, we just do some preliminary and qualitative study on earthquake damage distribution to provide a theoretical basis for the modeling of the 3-D damage models of multistory masonry structure in this paper.

\subsection{Earthquake Damage Distribution in Different Floors}

\subsubsection{Force Analysis of Multistory Masonry Structure}

The anti-seismic calculations of multistory masonry structure mainly consider horizontal earthquake action [2428]. As we know, the mass and stiffness of multistory masonry have usually a uniform distribution along the height, and the main deformation is shear deformation, and the main seismic response is the fundamental mode, so their seismic action can be calculated by using the equivalent base shear method [29]. In elastic stage, the seismic shear of multistory masonry structure is roughly inverted triangular distribution, 
as it is shown in Fig. (1). The seismic shear $V_{i}$ of the floor $i$ can be expressed as formula (2).

$V_{i}=\sum_{j=i}^{N} F_{j}=k \beta \gamma G \sum_{j=i}^{N} j$

where $k$ is the ratio of the seismic peak acceleration and acceleration of gravity, $\beta$ is the dynamic amplification factor, $\gamma$ is the mode-participation coefficient and $G$ is the floor gravity load representative value.

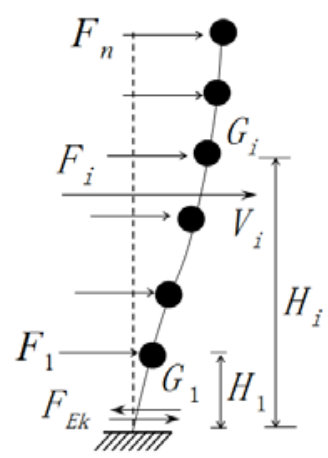

Fig. (1). Shear distribution.

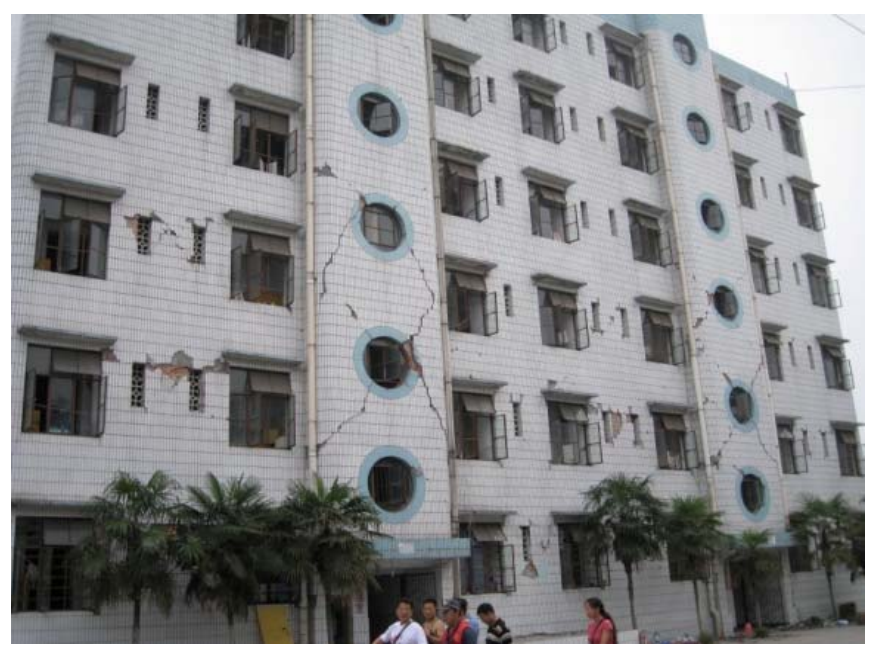

Fig. (2). The dormitory building of Hanwang technology school.

In addition, the previous earthquake damage showed that earthquake damage distribution and the distribution of seismic shear have a certain similarity. An example of Wenchuang earthquake is shown in Fig. (2), it's a male dormitory building of Hanwang technology school in Deyang, and its mass and stiffness are uniformly distributed along the height. According to the field survey, the building's seismic damage gradually became less from the bottom floor, until the top floor was not significantly damaged, the seismic damage distribution has obvious regularity.

\subsubsection{The Calculation Formula of Earthquake Damage Distribution of Different Floors}

Through the analysis of the force characteristics of multistory masonry structure under earthquake, it can be found that if floor damage number is proportional to its earthquake load, so under the damage level $d$, the component $m$ in mul- tistory masonry appears to be the seismic damage $l$, when the seismic damage index is $D_{d}$, the calculation formula of the damage percentage $P_{\mathrm{df} m i}$ of the component in the floor $i$ is:

$$
P_{\mathrm{df} m i}\left(D_{d}\right)=\frac{6 P_{m}\left[D_{d} \mid l\right]}{N(2 N+1)(N+1)} \sum_{j=i}^{N} j
$$

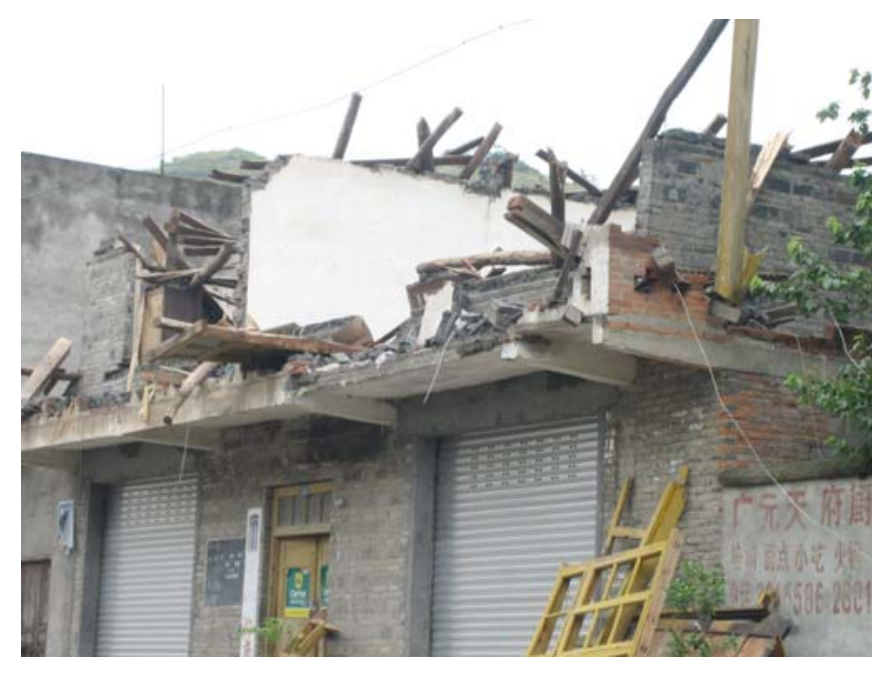

Fig. (3). A residential building in Qingxi, Qingchuan county.

In the Wenchuan earthquake, some buildings had weak floors, and these floors often had more serious damage, and other floors were less damaged, the reason was that when the weak floors were badly damaged, they produced energy dissipation and disaster mitigation effect, and reduced the damage of other floors. As shown in Fig. (3), it's a residential building in Qingxi, Qingchuan county of Guangyuan city, the top floor of this building is weak, the top roof was caved in the earthquake, the walls were out of plane collapsed, but the bottom had no obvious damage.

The formula (3) is the damage distribution under the premise, which is that each floor's stiffness changes uniformly along the height. Specific structures which have weak floors, and for those specific floors $s$, we should consider the seismic damage amplifying factor $\lambda_{s}$, and then the formula of earthquake damage percentage in different floors is:

$$
\begin{aligned}
& P_{\mathrm{d} f m s}\left(D_{d}\right)=\left(\lambda_{s}+\frac{6\left(1-\sum \lambda_{s}\right)}{N(2 N+1)(N+1)} \sum_{j=s}^{N} j\right) P_{m}\left[D_{d} \mid l\right] \\
& P_{\mathrm{df} m i}\left(D_{d}\right)=\frac{6\left(1-\sum \lambda_{s}\right) P_{m}\left[D_{d} \mid l\right]}{N(2 N+1)(N+1)} \sum_{j=i}^{N} j(i \neq s)
\end{aligned}
$$

According to a large number of earthquake disaster data of previous earthquakes and expert advices, the $\lambda_{s}$ of the fortification and non fortification structure, respectively take $0.3 \sim 0.4$ and $0.35 \sim 0.45$.

\subsection{The Structure Vulnerability Analysis Method to the Known Number of Damaged Components}

It should be pointed out that, if we have enough information about each floor area, the shear strength of masonry, earthquake protective measures and so on, based on the work 
Table 4. The range beyond strength rate corresponding to different damage levels [26, 27].

\begin{tabular}{|c|c|c|c|}
\hline Damage Grade & Upper and Lower Limits of Damage Index & Non Fortification Structure & Fortification Structure \\
\hline \hline Basic intact & {$[0,0.1]$} & $E \leq 1.0$ & $E \leq 1.0$ \\
\hline slight damage & {$[0.1,0.3]$} & $1.0<E \leq 1.3$ & $1.0<E \leq 1.35$ \\
\hline Medium damage & {$[0.3,0.55]$} & $1.3<E \leq 1.7$ & $1.35<E \leq 2.10$ \\
\hline Severe damage & {$[0.55,0.85]$} & $1.7<E \leq 2.0$ & $2.10<E \leq 2.5$ \\
\hline Eventual damage & {$[0.85,1.0]$} & $2.0<E$ & $2.5<E$ \\
\hline
\end{tabular}

Table 5. The component type and major position of earthquake damage.

\begin{tabular}{|c|c|}
\hline Component Type & Major Position of Seismic Damage $(k=1,2, \ldots, K$, Represent Different Positions of Component) \\
\hline Wall & $\begin{array}{l}\text { The hole corners of doors and windows, the walls between windows, the walls under windows, the junction of walls, walls } \\
\text { without holes, other parts (a total of } 6 \text { positions) }\end{array}$ \\
\hline Floor (roof) & Main part of roof, other parts (a total of 2 positions) \\
\hline
\end{tabular}

Table 6. The damage partition coefficient $\beta_{\text {sfmk }}$ of different positions in each component.

\begin{tabular}{|c|c|c|c|c|c|c|c|c|c|}
\hline \multicolumn{2}{|c|}{ Component Type } & \multicolumn{6}{|c|}{ Wall } & \multicolumn{2}{|c|}{ Roof } \\
\hline \multicolumn{2}{|c|}{ Earthquake Damage Type ( $l$ ) } & \multicolumn{8}{|c|}{$l=1,2,3,4$} \\
\hline \multicolumn{2}{|c|}{ Partition Coefficient ( $\beta_{\mathrm{s} f m k}$ ) } & $\beta_{\mathrm{sfm} 1}$ & $\beta_{\mathrm{sf} m 2}$ & $\beta_{\mathrm{sfm} 3}$ & $\beta_{\mathrm{sf} m 4}$ & $\beta_{\mathrm{sf} m 5}$ & $\beta_{\mathrm{sfm} 6}$ & $\beta_{\mathrm{sf} 31}$ & $\beta_{\mathrm{sf32}}$ \\
\hline \multirow{2}{*}{$\begin{array}{l}\text { Fortification } \\
\text { case }\end{array}$} & fortification structure & 0.3 & 0.1 & 0.2 & 0.2 & 0.1 & 0.1 & 0.3 & 0.7 \\
\hline & non fortification structure & 0.2 & 0.2 & 0.2 & 0.2 & 0.1 & 0.1 & 0.2 & 0.8 \\
\hline
\end{tabular}

demand, we can also get the exact damage state, the damage extent and amount of different components of each floor through structure vulnerability analysis method. The reference $[30,31]$ is used beyond strength rate $E$ for the vulnerability analysis of the fortification and non fortification structure, as shown in formula (6), in which the $V_{i}$ is the seismic shear of $i$ floor, $Q_{i}$ is the shear strength, and on the basis of statistical data, the reference gives the corresponding relationship between the building earthquake damage level and the $E$ value. Through calculation, we can get beyond strength rate $E$ of each floor, then according to the given corresponding relationship of earthquake damage level, seismic damage index and $E$ in Table 4, the floor damage state and damage number of each component can be known.

$$
E=\frac{V_{i}}{Q_{i}}
$$

\subsection{Seismic Damage Distribution in Different Parts of the Same Floor}

\subsubsection{The Major Position of Earthquake Damage of Each Component}

Through a lot of analysis to seismic damage, we conclude the major position of seismic damage of different components of multistory masonry structure, as it is showed in Table 5.

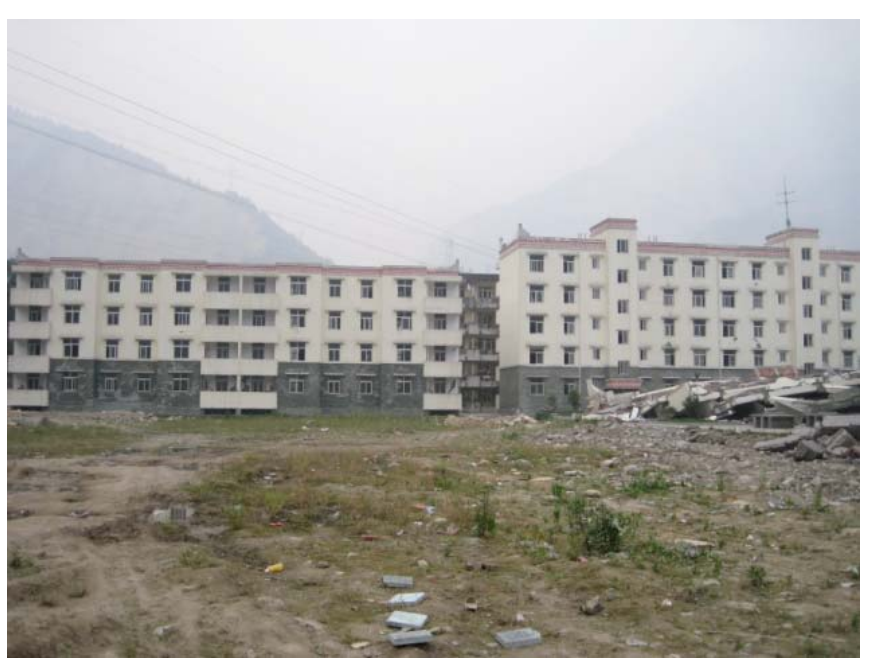

Fig. (4). The teachers' residential building.

\subsubsection{The Seismic Damage Distribution in Different Parts of Each Component}

The damage distribution in different positions of each component has certain regularity. We assumed $\beta_{\text {sfmk }}$ as the partition coefficient of earthquake damage at different positions of each component, then $\sum_{k=1}^{K} \beta_{\text {sfmk }}=1$. The value of $\beta_{\text {sfmk }}$ of different components shown in Table 6. 


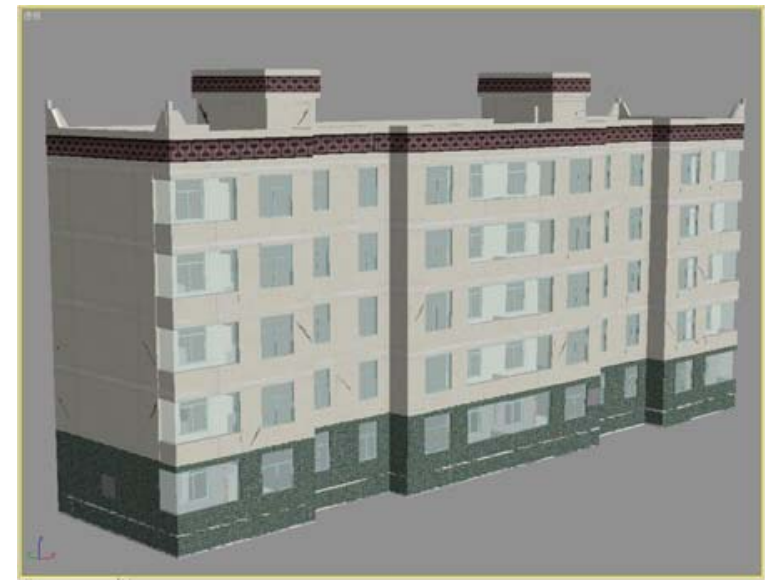

Fig. (5). Slightly damage model of the teachers' residential building.

\subsection{The Example of Seismic Damage Distribution}

Fig. (4) has shown a teachers' residential building of Xuankou middle school located in YingXiu, which was damaged in Wenchuan Earthquake. The building is a masonry structure, without weak story, the actual seismic damage level was serious. According to the formulation given above, a slight damage model using 3DS max software (as shown in Fig. (5)) can be built [32], we take the damage distribution of bearing wall as an example to give the distribution of earthquake damage, as shown in Table 7.

The total number $N_{1}$ of the bearing wall is known, using the formulation given above the amount of bearing walls with slight cracks in each floor and the distribution of cracks at different positions of bearing walls can be calculated.

\section{CONCLUSION}

Based on a large number of previous earthquake damage data, through mathematical means, this paper analyzes the amount of damage in each component of multistory masonry structure in different earthquake damage index quantitatively. Through structure analysis of multistory masonry structure and statistical analysis of the earthquake disaster data, this paper summed up laws of the damage distribution in different floors and different positions of each component on the same floor at different damage level, making it easier to get objective knowledge of the damage distribution of the multistory masonry structure when suffer from earthquake, meanwhile, it provided theoretical basis for building three dimensional disasters model of multistory masonry structure in seismic scene disaster simulation system.

The damage distribution of multistory masonry structures is affected by many factors [33-37], at present, based on the statistics and analyzing existing data, and in combination with the analysis results and professional advice, this paper did some preliminary and qualitative study on earthquake damage distribution that the damage of each floor is proportional to seismic shear force. With the deepening of the research, the damage distribution law which is close to reality need to be proposed, to quantify damage and to make an objective description for damage distribution of multistory masonry structure, to direct the construction of more realistic three dimensional disaster models of multistory masonry structure, and to establish the theoretical foundation for the seismic scene disaster simulation system.

\section{CONFLICT OF INTEREST}

The authors confirm that this article content has no conflict of interest.

\section{ACKNOWLEDGEMENTS}

This work was financially supported by the Jiangxi Science and Technology Plan Project (20141BBG70087), National Natural Science Foundation Major Research (91315301-10), and National Science and Technology Support Program (2012BAK15B02-01).

Table 7. Earthquake damage distribution rule of bearing wall.

\begin{tabular}{|c|c|c|c|c|c|}
\hline $\begin{array}{c}\text { Description of } \\
\text { Seismic Damage }\end{array}$ & \multicolumn{5}{|c|}{$\begin{array}{l}\text { Slight damage }(\mathrm{D} \in[0.1,0.3]) \text { : no damage or slight cracks occurred in bearing wall, roof and floor remained intact; part of the } \\
\text { bearing components have slight damage, or individual components have obvious damage, such as the roof collapsing, slope roof } \\
\text { slipping tile, cracks in parapet wall, obvious cracks in indoor plastering etc.; basic structure function is not affected, and it can be } \\
\text { repaired or to continue to use without repairing. }\end{array}$} \\
\hline \multirow{2}{*}{ Damage Position } & \multirow{2}{*}{ Damage type } & \multirow{2}{*}{ Number of component damage percentage } & \multicolumn{3}{|c|}{ Damage distribution } \\
\hline & & & Different floor & \multicolumn{2}{|c|}{ Same floor } \\
\hline \multirow{7}{*}{ Bearing Wall } & \multirow{6}{*}{ Light cracks } & \multirow{6}{*}{$\begin{array}{l}0 \text { to } 10 \% \text { of the walls appear the damage. The } \\
\text { percentage calculation formula for damage } \\
\text { number under different seismic damage index } \\
\qquad P_{1}\left[D_{2} \mid 1\right]=0.5(D-0.1)\end{array}$} & \multirow{6}{*}{$\begin{array}{l}P_{\mathrm{df} 11}(D)=0.27 P_{1}\left[D_{2} \mid l\right] \\
P_{\mathrm{df} 12}(D)=0.26 P_{1}\left[D_{2} \mid l\right] \\
P_{\mathrm{df13}}(D)=0.22 P_{1}\left[D_{2} \mid l\right] \\
P_{\mathrm{df1} 14}(D)=0.16 P_{1}\left[D_{2} \mid l\right] \\
P_{\mathrm{df} 15}(D)=0.09 P_{1}\left[D_{2} \mid l\right]\end{array}$} & $\beta_{\text {sfl1 }}$ & 0.3 \\
\hline & & & & $\beta_{\text {sfl2 }}$ & 0.1 \\
\hline & & & & $\beta_{\text {sfl3 }}$ & 0.2 \\
\hline & & & & $\beta_{\text {sfl4 }}$ & 0.2 \\
\hline & & & & $\beta_{\text {sfl5 }}$ & 0.1 \\
\hline & & & & $\beta_{\text {sfl6 }}$ & 0.1 \\
\hline & \multicolumn{2}{|c|}{ No obvious cracks, Serious cracks, collapse seismic damage, etc } & \multicolumn{3}{|l|}{ No } \\
\hline
\end{tabular}




\section{REFERENCES}

[1] C. X. Shi, Theory and Design of Masonry Structures, China Building Industry Press: Beijing, 1992.

[2] J. Kiyono, and A. Kalantari, "Collapse mechanism of adobe and masonry structures during the 2003 Iran bam earthquake", Bulletin of the Earthquake Research Institute, vol. 79, pp. 157-161, 2004.

[3] Z. Wang, "A preliminary report on the great wenchuan earthquake", Earthquake Engineering and Engineering Vibration, vol. 7, no. 2, pp. 225-234, 2008

[4] B. T. Sun, "The implementation of three-dimensional seismic damage simulation system", Earthquake Engineering and Engineering Vibration, vol. 30, no. 5, pp. 1-8, 2010.

[5] Q. Zhou, B. T. Sun, P. L. Yan, and P. Zhao, "Study on simulation technology of earthquake disaster scene", Advanced Materials Research, vol. 243-249, pp. 5111-5114, 2011.

[6] L. X. Zhang, B. T. Sun, J. P. Liu, and P. C. Wu, "Study on relevant problems of standard in classification of earthquake damage to buildings and special structures", Earthquake Engineering and Engineering Vibration, vol. 30, no. 2, pp. 39-44, 2010.

[7] ATC-13, "Earthquake Damage Evaluation Data for California", Applied Technology Council: California, 1985.

[8] NIBS, "Earthquake Loss Estimation", National Institute of Building Sciences: Washington, DC., 1994.

[9] SEAOC, Vision 2000 Committee, "Performance-Based Seismic Engineering of Buildings", Report Prepared by Engineers Association of California, Sacramento, California: USA, 1995.

[10] L. L. Xie, "On aseismic design model code", Recent Developments in World Seismology, no. 7, pp. 4-9, 2000.

[11] FEMA 356, "Prestandard and Commentary for the Seismic Rehabilitation of Buildings", Federal Emergency Management Agency: Washington, D. C., 2000.

[12] Grunthal G. European Macroseismic Scale 1998 (EMS-98), Luxembourg, 1998.

[13] GB/T 24335-2009, Classification of Earthquake Damage to Buildings and Special Structures (GB/T 24335-2009), Chinese Standards Press: Beijing, 2009.

[14] Gradation Criterion of Earthquake Damage of Building ((1990)No. 377), Chinese Standards Press: Beijing, 1990.

[15] GB/T 17742-1999, China Seismic Intensity Scale (GB/T 177421999), Chinese Standards Press: Beijing, 1999.

[16] GB/T 17742-2008, China Seismic Intensity Scale (GB/T 177422008), Chinese Standards Press: Beijing, 2008.

[17] Z. Q. Yin, Earthquake Disaster and Loss Forecasting Methods, Seismological Press: Beijing, 1996.

[18] GB/T 18208.3-2000, Post-Earthquake Field Works--Part 3: Code for Field Survey (GB/T 18208.3-2000), Chinese Standards Press: Beijing, 2000.

[19] JGJ 125-99, Standard of Dangerous Building Appraisal (JGJ 12599), China Building Industry Press: Beijing, 1999.

[20] G. Milani, "New trends in the numerical analysis of masonry struc- tures", Open Civil Engineering Journal, vol. 6, (Suppl. 1-M1), pp 119-120, 2012

[21] A. Karbassi, and P. Lestuzzi, "Fragility analysis of existing unreinforced buildings through a numerical-based methodology", Open Civil Engineering Journal, vol. 6, pp. 121-130, 2012.

[22] A. Araujo, P. B. Lourenço, D. V. Oliveira, and J. Leite, "Seismic assessment of St. James church by means of pushover analysis - before and after the New Zealand earthquake", Open Civil Engineering Journal, vol. 6, pp. 160-172, 2012.

[23] M. Acito, and G. Milani, "Homogenization approach for the evaluation of crack patterns induced by foundation settlement on an old masonry building", Open Civil Engineering Journal, vol. 6, pp. 215-230, 2012

[24] T. Paulay, and M. J. N. Priestley, Seismic Design of Reinforced Concrete and Masonry Buildings, John Wiley \& Sons: USA, 1992.

[25] R. W. Clough, and J. Penzien, Dynamics of Structures, Mc GrawHill: New-York, 1993

[26] A. K. Chopra, Dynamics of Structures: Theory and Applications to Earthquake Engineering, $2^{\text {nd }}$ ed., Prentice Hall, New Jersey: 2001.

[27] G. Q. Li, J. Li, and X. Z. Su, Seismic Design of Structure, China Building Industry Press: Beijing, 2006.

[28] X. L. Lv, D. Y. Zhou, and S. M. Li, Seismic Design Theory and Examples of Structure, Tongji University Press: Shanghai, 1995.

[29] GB50011-2001, Code for Seismic Design of Buildings (GB500112001), China Building Industry Press: Beijing, 2001.

[30] Z. Q. Yin, and S. W. Yang, Seismic Losses Analysis and Fortification Standard, Seismological Press: Beijing, 2004.

[31] Z. Q. Yin, Z. Zhao, and S. W. Yang, "Relation between vulnerability of buildings and earthquake acceleration spectra (1)", Earthquake Engineering and Engineering Vibration, vol. 23, no. 4, pp. 195-200, 2003.

[32] Q. Zhou, "Seismic Test and Elastic-Plastic Seismic Response Analysis of Masonry Structure", PhD Thesis, Harbin Engineering University, pp. 93-98, 2012.

[33] P. Fajfar, and H. Krawinkler, Nonlinear Seismic Analysis and Design of Reinforced Concrete Buildings, Taylor \& Francis: United Kingdom, 2005.

[34] A. K. Chopra, and R. K. Goel, "A Modal Pushover Analysis Procedure for Estimating Seismic Demands for Buildings Theory and Preliminary Evaluation", PEER Report, 2001.

[35] G. Magenes, "A Method for Pushover Analysis in Seismic Assessment of Masonry Buildings", In: 12 WCEE 2000: New Zealand, 1866.

[36] M. Calvi, "A displacement-based approach for vulnerability evaluation of classes of buildings", Journal of Earthquake Engineering vol. 3, no. 3, pp. 411-438, 1999.

[37] A. Tena-Colunga, and A. López-Blancas, "Allowable torsional eccentricity for the simplified method for the seismic analysis of low-rise confined masonry shear-wall buildings of Mexican codes", Open Civil Engineering Journal, vol. 5, pp. 132-142, 2011.

(C) Qiang and Bai-tao; Licensee Bentham Open.

This is an open access article licensed under the terms of the Creative Commons Attribution Non-Commercial License (http://creativecommons.org/licenses/ by-nc/3.0/) which permits unrestricted, non-commercial use, distribution and reproduction in any medium, provided the work is properly cited. 